\title{
Effect of treatment with human chorionic gonadotropin on day 5 after timed artificial insemination on fertility of lactating dairy cows
}

\author{
A. B. Nascimento, ${ }^{*} \dagger$ R. W. Bender, ${ }^{*}$ A. H. Souza, ${ }^{*}$ H. Ayres, ${ }^{*}$ R. R. Araujo, ${ }^{*}$ J. N. Guenther, ${ }^{*}$ \\ R. Sartori, $\dagger$ and M. C. Wiltbank ${ }^{*} \dagger^{1}$ \\ *Department of Dairy Science, University of Wisconsin-Madison, Madison 53706 \\ †Department of Animal Sciences, Escola Superior de Agricultura Luiz de Queiroz (ESALQ), University of Sao Paulo, 13418-900 Piracicaba, Brazil
}

\section{ABSTRACT}

Reproductive management programs that synchronize ovulation can ovulate a smaller than normal follicle, potentially resulting in inadequate progesterone $(\mathrm{P} 4)$ concentrations after artificial insemination (AI). Ovulation of the dominant follicle of the first follicular wave with human chorionic gonadotropin (hCG) treatment can produce an accessory corpus luteum and increase circulating P4 concentrations. This manuscript reports the results of 2 separate analyses that evaluated the effect of hCG treatment post-AI on fertility in lactating dairy cows. The first study used meta-analysis to combine the results from 10 different published studies that used hCG treatment on d 4 to 9 post-AI in lactating dairy cows. Overall, pregnancies per artificial insemination $(\mathrm{P} / \mathrm{AI})$ were increased $3.0 \%$ by $\mathrm{hCG}$ treatment post-AI $[34 \%(752 / 2,213)$ vs. $37 \%(808 / 2,184)$; Control vs. hCG-treated, respectively]. The second study was a field research trial in which lactating Holstein cows $(\mathrm{n}=2,979)$ from 6 commercial dairy herds were stratified by parity and breeding number and then randomly assigned to one of 2 groups: control (no further treatment, $\mathrm{n}=1,519$ ) or hCG [Chorulon i.m.: 2,000 IU (in 3 of the herds) or 3,300 IU (in 3 herds); $\mathrm{n}=1,460$ ] on d 5 after a timed AI (ovulation synchronized with Ovsynch, Presynch-Ovsynch, or Double-Ovsynch). In a subset of cows, the hCG profile and $\mathrm{P} 4$ changes were determined. Treatment with hCG increased P4 (4.3 vs. $5.3 \mathrm{ng} / \mathrm{mL}$ on d 12). Pregnancies per AI were greater in cows treated with hCG $(40.8 \% ; 596 / 1,460)$ than control (37.3\%; 566/1,519) cows. Interestingly, an interaction among treatment and parity was observed; primiparous cows had greater P/AI after hCG $(49.7 \% ; 266 / 535)$ than controls $(39.5 \% ; 215 / 544)$. In contrast, older cows receiving hCG $(35.7 \%$; 330/925) had similar $\mathrm{P} / \mathrm{AI}$ to controls $(36.0 \% ; 351 / 975)$. Thus, targeted use of hCG

Received July 2, 2012.

Accepted December 24, 2012.

${ }^{1}$ Corresponding author: wiltbank@wisc.edu on $\mathrm{d} 5$ after TAI enhances fertility about $3.0 \%$ (based on meta-analysis) to $3.5 \%$ (based on our field trial). Surprisingly, this fertility-enhancing effect of hCG was very large in first-lactation cows but not observed in older cows in the field study. Future research is needed to confirm these intriguing results and to determine why older cows did not have improved fertility after hCG treatment.

Key words: human chorionic gonadotropin (hCG), Ovsynch, dairy cow

\section{INTRODUCTION}

A decline in dairy cattle fertility, in terms of percentage of cows pregnant to an artificial insemination (P/AI), has been observed over the past 50 yr (Lucy, 2001). This has been attributed to a variety of factors including housing systems, herd size, management, metabolic and disease state, as well as changes in physiology related to higher milk production (Lopez et al., 2004; Caraviello et al., 2006; Wiltbank et al., 2006). Reproductive management programs that synchronize ovulation and therefore allow timed artificial insemination (TAI) have become widely used in the dairy industry to improve reproductive efficiency (Pursley et al., 1995; Caraviello et al., 2006; Bisinotto and Santos, 2011). Timed AI programs result in an increased service rate and recent advances in these programs have also demonstrated improved fertility with programs that use targeted presynchronization (Bisinotto and Santos, 2011; Pursley and Martins, 2011; Wiltbank et al., 2011). One of the hallmarks of most TAI is that they induce a synchronized ovulation of a dominant follicle. Whereas ovulation of a smaller follicle may be positive for oocyte quality, it would result in production of a smaller corpus luteum (CL) that may produce lower progesterone (P4) concentrations than are optimal for fertility (Vasconcelos et al., 2001; Perry et al., 2005; Gaja et al., 2008) This problem is further exaggerated due to the high metabolism of $\mathrm{P} 4$ that is characteristic of high-producing dairy cows (Sangsritavong et al., 2002; Wiltbank et al., 2006). 
Progesterone is essential for pregnancy maintenance, playing a decisive role in stimulating production of a large range of endometrial compounds, growth factors, immunosuppressive agents, enzymes, ions, and steroids (Geisert et al., 1992; Hugentobler et al., 2010; Forde et al., 2011). Several studies have shown that increasing concentrations of circulating $\mathrm{P} 4$ in the immediate postconception phase can hasten elongation of the embryo and increase embryonic interferon-tau production (Mann et al., 2006; Carter et al., 2008; Lonergan, 2011). In addition, lower circulating $\mathrm{P} 4$ during the post-AI period are associated with reduced fertility in lactating dairy cows in some studies (Stevenson et al., 1993; Gümen and Wiltbank, 2005, Diskin et al., 2006). Based on these observations, numerous studies have attempted to supplement P4 during the post-AI period to increase pregnancy or calving risk with surprisingly inconsistent results (Wiltbank et al., 2011). One common method for supplementing P4 after AI is induction of ovulation of the dominant follicle of the first follicular wave using either GnRH or human chorionic gonadotropin (hCG) treatment to produce an accessory CL. As expected, ovulation of an accessory CL subsequently increased circulating P4 concentrations (Helmer and Britt, 1986; Santos et al., 2001; Stevenson et al., 2007); however, increases in pregnancy risk have not been as consistent. The present study presents a meta-analysis of previous published manuscripts $(\mathrm{n}=10)$ that have evaluated the effects of post-AI treatment with hCG on fertility in lactating dairy cows. As discussed below, we found a small but significant effect of hCG treatment on fertility in these published results. Therefore, we designed a manipulative experiment to evaluate whether treatment with hCG on d 5 after a TAI would result in increased fertility to TAI. To have sufficient statistical power to detect small, but economically important treatment effects of hCG, this study was done on 6 different dairies with almost 3,000 lactating dairy cows included in the research. Our primary hypothesis was that hCG treatment on $\mathrm{d} 5$ would increase $\mathrm{P} / \mathrm{AI}$ following a synchronized ovulation and TAI program. Further, we hypothesized that this effect would be found in either primiparous or multiparous cows and after either first or later AI.

\section{MATERIALS AND METHODS}

\section{Experiment 1: Meta-Analysis of Previous Studies Using hCG After Al}

Studies comparing hCG-treated cows to nontreated controls were selected from the literature. We eliminated all studies that were performed in beef cattle or dairy heifers and only included trials using lactating dairy cows in which we could obtain the precise number of control and hCG-treated cows and the number of pregnancies for each group. A total of 10 studies were included in the trial (Table 1). A binomial data set with conception outcomes for each trial was reconstructed based on the $\mathrm{P} / \mathrm{AI}$ proportions reported in each trial as recommended elsewhere (Hamza et al., 2008). A final table combining all reconstructed data sets from all trials was analyzed with a mixed logistic regression model (proc Glimmix of SAS; version 9.3 for Windows, SAS Institute Inc., Cary, NC) using treatment as a fixed effect, and study, which was included in the model, as a random effect.

\section{Experiment 2: Animals and Management}

This study was conducted on 6 different dairy farms located in south-central Wisconsin using lactating Holstein cows $(\mathrm{n}=2,979)$ that had ovulation synchronized using Ovsynch-type programs (Pursley et al., 1995). Cows were housed in freestall barns, milked 3 times a day, and fed TMR typical of high-producing herds. The experiment was replicated 5 times (A to E) from March 2007 through November 2009. The season of breeding was defined as cool (October to March), or warmer season (April to September). Sixteen hundred and eighty-five cows were bred during cooler periods of the year, and 1,294 cows during warmer periods.

\section{Experimental Design}

On all farms, early postpartum cows (42 \pm 3 DIM; $\mathrm{n}=1,702)$ were given the standard presynchronization treatment used on the farm, either Double-Ovsynch (Souza et al., 2008) or Presynch-Ovsynch (Moreira et al., 2001), and TAI. In addition, cows detected open and returning from later services $(\mathrm{n}=1,277)$ were subjected to a resynchronization protocol ( $>95 \%$ Resynch-32) and received TAI. During the Double-Ovsynch treatment, the preOvsynch was done as follows: $100 \mu \mathrm{g}$ of $\mathrm{GnRH}$ (d $58 \pm 3 ; 2 \mathrm{~mL}$ of Cystorelin, Merial Ltd., Duluth, $\mathrm{GA})$, followed by an injection of $\mathrm{PGF}_{2 \alpha}(5 \mathrm{~mL}$ of $\mathrm{Lu}-$ talyse; Pfizer Animal Health, New York, NY) 7 d later and GnRH $72 \mathrm{~h}$ after $\mathrm{PGF}_{2 \alpha}$. The Breeding-Ovsynch-56 protocol was done $7 \mathrm{~d}$ later, as follows: $\mathrm{GnRH}, \mathrm{PGF}_{2 \alpha}$ $7 \mathrm{~d}$ later, GnRH $56 \mathrm{~h}$ after $\mathrm{PGF}_{2 \alpha}$, and TAI $16 \mathrm{~h}$ later. The Presynch-Ovsynch was performed as follows: the presynchronization was done with 2 injections of $\mathrm{PGF}_{2 \alpha}$ $14 \mathrm{~d}$ apart, and the Ovsynch protocol was initiated 11 or $12 \mathrm{~d}$ after the final $\mathrm{PGF}_{2 \alpha}$ treatment with an identical Breeding-Ovsynch-56 protocol as described above. The resynchronization protocol also used the identical Breeding-Ovsynch-56 protocol as described above. On d 5 after TAI, lactating cows $(n=2,979)$ were strati- 
Table 1. List of results for each of the publications that were used in the meta-analysis and the final results from the analysis

\begin{tabular}{|c|c|c|c|c|c|}
\hline Publication & Dose $/$ Day $^{1}$ & $\begin{array}{c}\text { Control }^{2} \\
{[\% \text { (no./total) }]}\end{array}$ & $\begin{array}{l}\text { Treatment }^{3} \\
{[\% \text { (no./total) }]}\end{array}$ & $\begin{array}{c}\text { Effect }^{4} \\
(\%)\end{array}$ & $P$-value \\
\hline Beltran and Vasconcelos (2008) & $1,500 \mathrm{IU}, \mathrm{d} 5$ & $13.5(7 / 52)$ & $27.5(14 / 51)$ & +14.0 & NS \\
\hline Fischer-Tenhagen et al. (2010) & $2,500 \mathrm{IU}, \mathrm{d} 4$ & $36.5(156 / 427)$ & $37.1(160 / 431)$ & +0.6 & NS \\
\hline Kendall et al. (2009) & $1,500 \mathrm{IU}, \mathrm{d} 5$ & $41.3(118 / 286)$ & $45.2(123 / 272)$ & +3.9 & NS \\
\hline Santos et al. (2001) & $3,300 \mathrm{IU}, \mathrm{d} 5$ & $38.7(79 / 203)$ & $45.8(93 / 203)$ & +7.1 & $<0.01$ \\
\hline Schmitt et al. (1996) & $3,000 \mathrm{IU}, \mathrm{d} 5 / 6$ & $23.5(24 / 102)$ & $24.2(24 / 99)$ & +0.7 & $<0.91$ \\
\hline Walton et al. $(1990)^{5}$ & $1,500 \mathrm{IU}, \mathrm{d} 5$ & $57.1(8 / 14)$ & $57.1(8 / 14)$ & 0.0 & NS \\
\hline Total & & $34.0(752 / 2,213)$ & $37.0(808 / 2,184)$ & +3.0 & 0.04 \\
\hline
\end{tabular}

${ }^{1}$ Dose of human chorionic gonadotropin (hCG) per day after AI.

${ }^{2}$ Control percentage of cows pregnant to $\mathrm{AI}(\mathrm{P} / \mathrm{AI})$.

${ }^{3}$ Treatment with hCG percentage $\mathrm{P} / \mathrm{AI}$.

${ }^{4}$ Effect on percentage $\mathrm{P} / \mathrm{AI}$.

${ }^{5}$ Only hCG treatment group shown, reference publication for other treatments.

${ }^{6}$ Only hCG treatment shown for timed artificial insemination (TAI) breeding technique, reference publication for other treatments.

fied by parity and breeding number, and then randomly assigned to 1 of 2 treatments: (1) no further treatment (control; $\mathrm{n}=1,519$ ); or (2) 2,000 or $3,300 \mathrm{IU}$ of $\mathrm{hCG}$ i.m. (Chorulon, Intervet, Millsboro, NJ; $\mathrm{n}=1,460$ ).

\section{Ultrasound Scanning for Ovarian Response to Treatment}

A subset of 90 cows from one of the farms was analyzed for double-ovulation rate in response to the Double-Ovsynch protocol to detect extra CL before treatment with hCG. Extra CL before treatment was not considered an effect of the hCG treatment. Ovarian structures on d 5 and 12 were scanned and mapped using transrectal ultrasonography $(7.5-\mathrm{MHz}$ transrectal probe, Easi-Scan1/portable ultrasound, BCF Technology Ltd., Livingston, UK). These ultrasound measurements allowed calculation of (1) percentage of cows having induced ovulation; (2) number of CL on d 5 and 12; (3) volume of the primary CL before and after treatment; (4) total luteal volume before and after treatment. Corpora lutea were assumed to be spherical by averaging the largest cross-sectional width and height. Volume was calculated as follows: $4 / 3 \times \mathrm{R}^{3} \times$ $\pi$, where $\mathrm{R}$ (radius) = average diameter $/ 2$.

\section{Progesterone and hCG Assays}

Blood samples were collected via venipuncture of the median caudal vein or artery into evacuated tubes (Vacutainer, BD Biosciences, Franklin Lakes, NJ) on d 5 and 12 after TAI for later analysis of serum P4, with the first sample collected immediately before administration of treatment. The samples were centrifuged
$(3,000 \times g$ for $20 \mathrm{~min})$, and serum was harvested and stored at $-20^{\circ} \mathrm{C}$ until assayed for $\mathrm{P} 4$ using a solidphase, no-extraction radioimmunoassay (Coat-a-Count Progesterone, Diagnostic Products Corp., Los Angeles, CA); the inter-assay CV was $4 \%$. A second subset of cows $(\mathrm{n}=5)$ were treated i.m. with $3,300 \mathrm{IU}$ of $\mathrm{hCG}$ and blood samples were collected at $0,2,4,6,8,10,12$, $24,48,72,96,120,144$, and $168 \mathrm{~h}$ after treatment to characterize the circulating hCG profile. Human chorionic gonadotropin was then quantified with the Coata-Count IRMA assay (Diagnostic Products Corp.); the intra-assay CV was $2.2 \%$.

\section{Statistical Analysis}

Cows within weekly breeding cohort groups were blocked according to parity (primiparous vs. multiparous) and number of breedings (first vs. later), and then randomly assigned to each of the 2 treatments. Binomial data were analyzed with PROC GLIMMIX of SAS. The logistic regression model was selected by backward elimination based on the Wald statistics criterion when $P>0.20$. The final model included the effects of treatment, number of times bred, parity, and two-way interactions, with cow within trial treated as a random effect. The Covtest ZeroG procedure of GLIMMIX was used to test the significance of random variables included in the logistic model. Because no interaction of treatment and trial was noted, data from all trials were combined in the final $\mathrm{P} / \mathrm{AI}$ analysis, with trial kept in the model as a random effect. The GLM procedure of SAS was used to evaluate circulating $\mathrm{P} 4$ on $\mathrm{d} 5$ and 12 post-TAI. The MIXED procedure of SAS was used to analyze the circulating hCG profile, 
Table 2. The effects of human chorionic gonadotropin (hCG) on pregnancies per AI (P/AI) in the 5 different trials that were included in this study

\begin{tabular}{|c|c|c|c|c|}
\hline \multirow{2}{*}{$\begin{array}{l}\operatorname{Trial}^{1} \\
\text { (hCG dose i.m.) }\end{array}$} & \multicolumn{2}{|c|}{ Treatment [no./total (\%)] } & \multirow{2}{*}{$\begin{array}{c}\text { Difference } \\
\text { in } \mathrm{P} / \mathrm{AI}(\%)\end{array}$} & \multirow[b]{2}{*}{$P$-value } \\
\hline & Control & $\mathrm{hCG}$ & & \\
\hline A $(2,000 \mathrm{IU})$ & 95/193 (49.2) & 93/197 (47.2) & -2.0 & 0.19 \\
\hline $\mathrm{B}(2,000 \mathrm{IU})$ & $119 / 311(38.3)$ & $114 / 299(38.1)$ & -0.2 & 0.42 \\
\hline C (2,000 IU) & $101 / 273(37.0)$ & $119 / 272(43.7)$ & +6.7 & 0.05 \\
\hline $\mathrm{D}(3,300 \mathrm{IU})$ & $73 / 199(36.6)$ & $66 / 160(41.2)$ & +4.8 & 0.10 \\
\hline $\mathrm{E}(3,300 \mathrm{IU})$ & $178 / 543(32.8)$ & $204 / 532(38.4)$ & +5.6 & $<0.01$ \\
\hline Overall & $566 / 1,519(37.3)$ & $596 / 1,460(40.8)$ & +3.5 & 0.01 \\
\hline
\end{tabular}

${ }^{1}$ Trial E included 2 commercial farms, whereas the rest of the trials included only a single commercial farm.

with cow treated as a random effect and the subject of repeated measures analysis. A probability of $P<$ 0.05 was considered to be significant, and probabilities between 0.05 and 0.10 were discussed as tendencies.

\section{RESULTS}

\section{Experiment 1: Results of Meta-Analysis}

Table 1 shows the results from the meta-analysis. Only 2 of the 10 studies found a significant effect of hCG treatment; however, the overall meta-analysis detected a significant $(P=0.04)$ effect of hCG treatment on $\mathrm{P} / \mathrm{AI}$ in lactating dairy cows. A total increase was observed of $3.0 \%$ due to hCG treatment or an $8.8 \%$ relative increase in $\mathrm{P} / \mathrm{AI}(3 \% / 34 \%)$. It was not possible to validly analyze an effect of parity in these studies due to a lack of information in some of the studies.

\section{Pregnancies per Al}

Table 2 shows the results from each of the 5 trials that were included in the manipulative study. Overall, a significant $(P=0.01)$ effect of hCG treatment i.m. on $\mathrm{P} / \mathrm{AI}$ was noted, with a $3.5 \%$ increase (from 37.3 to $40.8 \%$ ) in absolute terms and a relative increase of $9.4 \%(3.5 \% / 37.3 \%)$ in P/AI. A significant effect of hCG was seen in only 2 of the 5 trials, with a tendency for an effect $(P=0.10)$ in another trial and a slightly negative (not significant) effect of hCG treatment in 2 of the trials. Table 3 shows the $P$-values that were determined from the final logistic regression model for P/AI from this study. Significant effects were observed for treatment, times bred, and parity. The $\mathrm{P} / \mathrm{AI}$ at first postpartum AI was greater $(49.8 \% ; 653 / 1,312)$ than at second or later AI $(33.1 \% ; 423 / 1,277)$. The parity effect was also clear, with cows in first lactation having greater $\mathrm{P} / \mathrm{AI}(44.6 \% ; 481 / 1,079)$ than cows in second or later lactation $(35.8 \% ; 681 / 1,900)$. No treatment by times bred interaction $(P=0.18)$ was noted. In addition, trial, season, technician within farm, and mean- ingful two-way interactions with these variables did not have significant effects on $\mathrm{P} / \mathrm{AI}(P>0.10)$.

The most surprising effect was the treatment by parity interaction $(P<0.01)$ that is clearly demonstrated in Table 4. Treatment with hCG enhanced $\mathrm{P} / \mathrm{AI}$ in first-lactation cows $(P<0.01)$ but not in the older cows $(P=0.98)$. A $10.2 \%$ increase was observed for $\mathrm{P} / \mathrm{AI}$ in primiparous cows treated with hCG, which calculates to a relative increase of $25.3 \%(10.2 / 39.5)$ in $\mathrm{P} / \mathrm{AI}$. No indication of a numerical effect of hCG $(-0.3 \%)$ in multiparous cows was noted.

To determine the consistency of this parity effect, all trials were analyzed for the effect of hCG treatment within the 2 parity groups: primiparous or multiparous (Table 5). In all trials, treatment with hCG produced a greater response in primiparous than multiparous cows. The advantage ranged from $5.5 \%$ in trial C to $20.1 \%$ in trial D. Nevertheless, only trials D and E had an hCG effect in primiparous cows that was significant $(P$ $=0.05$ or 0.06 ) based on simple Chi-squared analysis. In no case did the hCG effect approach significance in multiparous cows.

\section{Ovulation, P4 Responses, and hCG Profile}

Table 6 shows the physiological effects of hCG treatment on circulating $\mathrm{P} 4$ and ovarian structures that was performed in one of the independent trials (trial C) that used the 2,000 IU dose of hCG. Nearly $80 \%$ of the cows treated with 2,000 IU of hCG i.m. on d 5 after TAI responded with ovulation of one $(\mathrm{n}=23)$ or

Table 3. Final $P$-values for variables kept in the final logistic regression model for pregnancies per AI in lactating Holstein cows treated with hCG $5 \mathrm{~d}$ after timed AI versus control (no further treatment)

\begin{tabular}{lr}
\hline Variable & $P$-value \\
\hline Treatment & 0.01 \\
Times bred & $<0.01$ \\
Parity & $<0.01$ \\
Treatment $\times$ Times bred & 0.18 \\
Treatment $\times$ Parity & $<0.01$ \\
\hline
\end{tabular}


Table 4. Effects of treatment [human chorionic gonadotropin (hCG) vs. control] according to parity number on pregnancy per AI

\begin{tabular}{lccc}
\hline Parity & Control & hCG & \\
& {$[$ no./total $(\%)]$} & {$[$ no./total $(\%)]$} & $P$-value \\
\hline 1 & $215 / 544(39.5)$ & $266 / 535(49.7)$ & $<0.01$ \\
$\geq 2$ & $351 / 975(36.0)$ & $330 / 925(35.7)$ & 0.98 \\
\hline
\end{tabular}

more $(\mathrm{n}=14)$ follicles. As a result, total number of CL almost doubled in the hCG-treated cows with a corresponding increase in total CL volume. Nevertheless, treatment with hCG did not seem to alter the volume of the original CL that was present at the time of $\mathrm{hCG}$ treatment on d 5 post-TAI (Table 5 ).

Circulating P4 concentrations were similar in cows in the hCG group compared with controls on d 5 after TAI. The circulating P4 concentrations were greater on d 12 in cows receiving hCG than in control cows. Thus, circulating $\mathrm{P} 4$ increased to a greater extent in hCG-treated cows by d 12 after AI ( $7 \mathrm{~d}$ after hCG) as compared with controls (360 vs. $259 \%$; Table 6).

The hCG profile following treatment with $3,300 \mathrm{IU}$ of hCG i.m. is shown in Figure 1. Circulating hCG increased rapidly, with $\mathrm{hCG}$ detected at the earliest time point that was measured $(2 \mathrm{~h}$ after $\mathrm{hCG}$ treatment). Maximal hCG concentrations were achieved by $4 \mathrm{~h}$ after treatment with a plateau in elevated $\mathrm{hCG}$ concentrations from 4 to $12 \mathrm{~h}$ after $\mathrm{hCG}$ treatment (Figure 1). The hCG concentrations began to decline at 24 and $48 \mathrm{~h}$ after hCG with basal concentrations (not different from time 0) achieved by $72 \mathrm{~h}$ after treatment. Nevertheless, the variation in circulating hCG among cows was quite remarkable, as represented by the large standard error bars.

\section{DISCUSSION}

This study provides the most complete analyses to date of the effects of hCG treatment on d 5 after AI on fertility in lactating dairy cows. Our original hypothesis was that treatment with hCG on d 5 after AI would increase P4 concentrations and increase fertility, particularly in cows that ovulate a smaller follicle following a well-synchronized fixed TAI program, such as Double-Ovsynch or Presynch-Ovsynch. We used 2 experimental approaches, a meta-analysis of previously published studies on hCG usage in lactating dairy cows and a primary research trial on hCG treatment with a large number of dairy cows on 6 commercial dairy farms to conclusively test the outcome of the meta-analysis. The 2 approaches provided complementary data and should be useful for future research trials or economic analyses that focus on the potential usefulness of $\mathrm{hCG}$ treatment in dairy cattle.

The meta-analysis included 10 trials with a total of 4,397 lactating cows included in the investigation.

Table 5. Effect of human chorionic gonadotropin (hCG) treatment on pregnancies per AI (P/AI) in primiparous and multiparous cows in each individual trial

\begin{tabular}{lccc}
\hline & $\begin{array}{c}\text { Control } \\
\text { [no./total }(\%)]\end{array}$ & $\begin{array}{c}\text { hCG } \\
\text { [no./total }(\%)]\end{array}$ & $\begin{array}{c}\text { Difference } \\
\text { in P/AI (\%) }\end{array}$ \\
\hline A - Primiparous & $39 / 65(60.0)$ & $43 / 70(61.4)$ & +1.4 \\
A - Multiparous & $56 / 128(43.8)$ & $50 / 127(39.4)$ & -4.4 \\
Trial A - Parity difference & $42 / 114(36.8)$ & $49 / 117(41.9)$ & +5.8 \\
B - Primiparous & $77 / 197(39.1)$ & $65 / 182(35.7)$ & +5.1 \\
B - Multiparous & & & -3.4 \\
Trial B - Parity difference & $40 / 102(39.2)$ & $54 / 110(49.1)$ & +8.5 \\
C - Primiparous & $61 / 171(35.7)$ & $65 / 162(40.1)$ & +9.9 \\
C - Multiparous & & & +4.4 \\
Trial C - Parity difference & $32 / 78(41.0)$ & $33 / 56(58.9)$ & +5.5 \\
D - Primiparous & $41 / 121(33.9)$ & $33 / 104(31.7)$ & +17.9 \\
D - Multiparous & $62 / 185(33.5)$ & $87 / 182(47.8)$ & -2.2 \\
Trial D - Parity difference & $116 / 358(32.4)$ & $117 / 350(33.5)$ & +20.1 \\
E - Primiparous & & & +14.3 \\
E - Multiparous & & +1.1 \\
Trial E - Parity difference & $215 / 544(39.5)$ & $266 / 535(49.7)$ & +13.2 \\
Overall - Primi & $351 / 975(36.0)$ & $330 / 925(35.7)$ & +10.2 \\
Overall - Multi & & & -0.3 \\
Overall - Parity difference & & & +10.5 \\
\hline
\end{tabular}

${ }^{1}$ In all trials, the primiparous cows were found to have an advantage over the multiparous cows in difference in $\mathrm{P} / \mathrm{AI}$. 


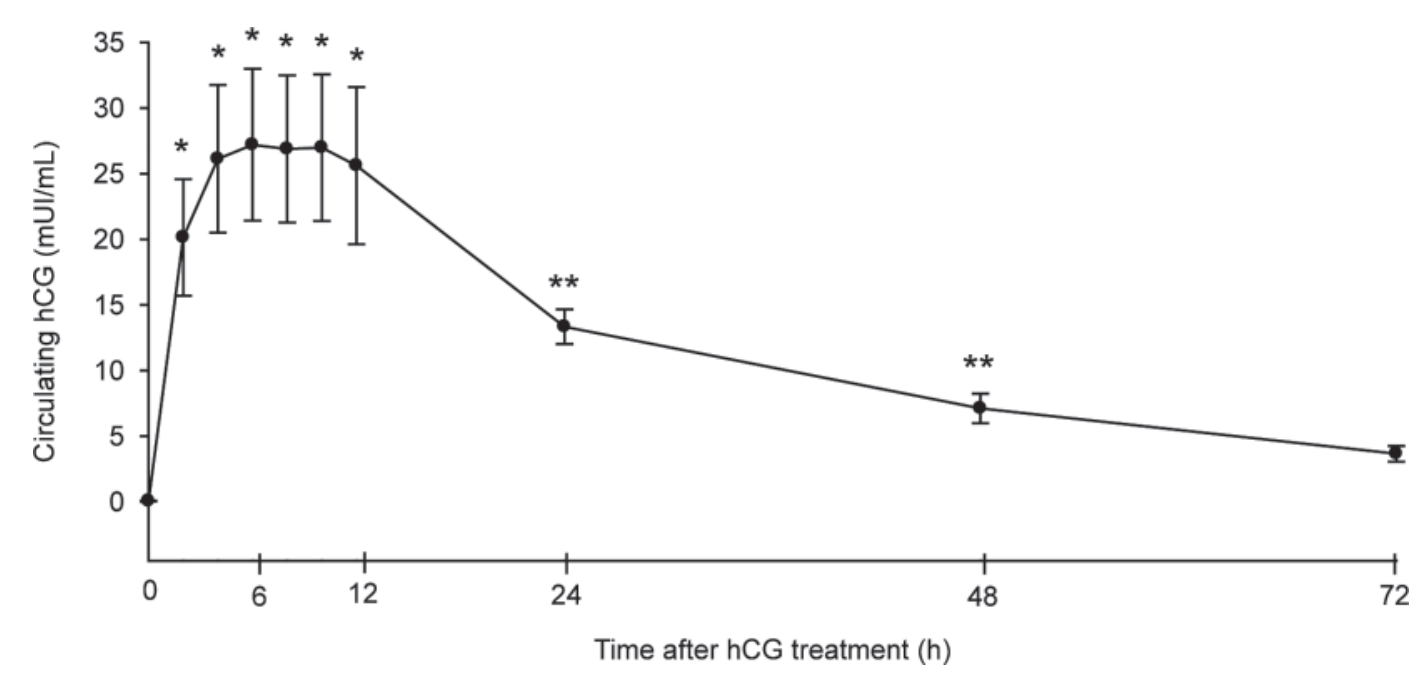

Figure 1. Circulating profile of human chorionic gonadotropin (hCG) following exogenous hCG treatment (3,300 IU i.m.) in lactating dairy cows $(\mathrm{n}=5)$. ${ }^{*}$ Significantly greater than that at $0 \mathrm{~h} ; P<0.05$; **tended to be greater than that at $0 \mathrm{~h} ; P<0.10$.

The effect of hCG was modest, with a $3 \%$ absolute increase or a calculated $8.8 \%$ relative increase $(3 \%$ increase $/ 34 \%)$. The effect of hCG was found to be statistically significant $(P=0.04)$.

The results of the manipulative trial included data from 2,979 lactating dairy cows on 6 commercial dairies that represented the results of 5 independent research trials done in our laboratory. In 3 of the trials (3 dairy herds), a dose of 2,000 IU of hCG i.m. was utilized, whereas, in the other 2 trials (3 dairy herds), a dose of 3,300 IU i.m. was utilized. No significant effect of hCG dose was detected in our statistical model, although 2 of the 3 trials that detected a significant positive effect of hCG treatment used the higher dose (3,300 IU). Nevertheless, a recent review of hCG supplementation post-AI (De Rensis et al., 2010) indicated that dose of hCG, which ranged from 1,000 to $10,000 \mathrm{IU}$, did not seem to affect ovarian response. Based on the wide range of hCG doses that have been used in previous studies and the independent planning of each research trial with each herd veterinarian, the dose effect of hCG was not evaluated within a single trial and 2 distinct doses of hCG were utilized in this study with only a single dose used on a specific farm. Combining the results from these independent trials that were performed by our laboratory personnel indicated that treatment with hCG increased $(P=0.01)$ fertility an average of $3.5 \%$ in absolute terms or $9.4 \%$ in relative terms $(3.5 \%$ increase $/ 37.5 \%$ ). Some variation was observed between trials in our manipulative study, but it seemed similar to the variation observed in the previously published studies analyzed in the meta-analysis (Table 1). Thus, although the overall hypotheses were clearly supported, some perplexing results were observed that need to be discussed and perhaps addressed in future research.

The first particularly puzzling result came from the parity analysis of the manipulative study. It was not surprising to find an effect of parity, as numerous other studies have shown that first-parity cows generally have higher fertility than older cows-particularly

Table 6. Effects of human chorionic gonadotropin (hCG; 2,000 IU i.m.) on ovulation response, corpus luteum (CL) volume for primary and accessory CL, and circulating P4 on d 5 and 12 post-TAI

\begin{tabular}{|c|c|c|c|c|}
\hline \multirow[b]{3}{*}{ Item } & \multicolumn{4}{|c|}{ Treatment } \\
\hline & \multicolumn{2}{|c|}{ Control (44) } & \multicolumn{2}{|c|}{$\mathrm{hCG}^{1}(46)$} \\
\hline & Day 5 & Day 12 & Day 5 & Day 12 \\
\hline Overall ovulation response [no./total (\%)] & \multicolumn{2}{|c|}{$2 / 44(4.5 \%)^{\mathrm{a}}$} & \multicolumn{2}{|c|}{$36 / 46(78.3 \%)^{\mathrm{b}}$} \\
\hline Progesterone $(\mathrm{ng} / \mathrm{mL})$ & $1.67^{\mathrm{a}}$ & $4.32^{\mathrm{b}}$ & $1.57^{\mathrm{a}}$ & $5.65^{\mathrm{c}}$ \\
\hline CL (no.) & $1.11^{\mathrm{a}}$ & $1.16^{\mathrm{a}}$ & $1.11^{\mathrm{a}}$ & $2.26^{\mathrm{b}}$ \\
\hline Primary CL volume $\left(\mathrm{cm}^{3}\right)$ & $5.38^{\mathrm{a}}$ & $11.03^{\mathrm{b}}$ & $5.1^{\mathrm{a}}$ & $9.8^{\mathrm{b}}$ \\
\hline Total CL volume $\left(\mathrm{cm}^{3}\right)$ & $5.45^{\mathrm{a}}$ & $11.27^{\mathrm{b}}$ & $5.1^{\mathrm{a}}$ & $14.88^{\mathrm{c}}$ \\
\hline
\end{tabular}

${ }^{\mathrm{a} c} \mathrm{C}$ Means with different superscripts within rows are different; $P<0.05$.

${ }^{1}$ A total of 2,000 IU given at $5 \mathrm{~d}$ after TAI. 
when cows are bred after well-synchronized fixed TAI protocols (Brusveen et al., 2008; Giordano et al., 2012; Souza et al., 2008). However, the treatment by parity interaction was very significant, and the reason for this interaction is demonstrated plainly in Table 4 . Treatment with hCG induced a 10\% absolute increase in fertility (25\% relative increase) in first-parity cows with no indication of any effect of hCG in older cows (Control $=36.0 \%$ vs. $\mathrm{hCG}=35.7 \%)$. We were unable to confirm this parity effect in the meta-analysis due to lack of clear parity information in most of the studies. In some studies an absence of parity information (Walton et al., 1990; Schmitt et al., 1996b; Hanlon et al., 2005; Vasconcelos et al., 2011) or parity comparisons (Vasconcelos et al., 2011) was noted. Two studies did not observe any parity effect between primiparous and multiparous cows supplemented with hCG (Beltran and Vasconcelos, 2008; Fischer-Tenhagen et al., 2010). Intriguingly, one study showed higher conception rates (20\% increase) in multiparous hCG-treated (56\%) cows compared with multiparous controls (36\%), but no effect ( $5 \%$ decrease) in primiparous hCG-treated cows (33\%) versus controls (38\%; Kendall et al., 2009). Similarly, one study observed higher conception rates for second lactation (Control $=26.0$ vs. $\mathrm{hCG}=39.6 \%$ ) but no effect of hCG in first or third and later lactations (Stevenson et al., 2007). Conversely, one study in the meta-analysis had results that were similar to our study, with hCG increasing fertility in primiparous but not in multiparous cows; however, no interaction between treatment and parity was detected (Santos et al., 2001). Our experiment does not provide a clear explanation for the differences between studies in the discrepancies between parities in the fertility effects of $\mathrm{hCG}$. The greater fertility effect of $\mathrm{hCG}$ in primiparous than multiparous cows in our study was remarkable, unexpected, and not easy to explain. Primiparous cows have many physiological and pathological differences from older lactating dairy cows, including lower milk production, fewer reproductive problems, increased anovulation, reduced disease problems, and reduced body and organ sizes (Bamber et al., 2009; Dubuc et al., 2012). Any or all of these issues may underlie the parity differences that were observed between studies or within our manipulative study.

The second major puzzle from our results was the surprisingly low magnitude of the increase in fertility following treatment with hCG. It seems possible that part of this effect is due to the previously discussed parity enigma, as about $64 \%$ of the cows in this study were older cows. Nevertheless, we expected a much greater effect of hCG treatment, as $\mathrm{P} 4$ concentrations are less than half the concentrations in lactating dairy cows ovulating after Double-Ovsynch compared with normally ovulating heifers (Nascimento et al., 2012). Our previous study indicated that hCG treatment on d 5 produced $\mathrm{P} 4$ concentrations that approached, but were still statistically lower than, $\mathrm{P} 4$ concentrations in heifers by $4 \mathrm{~d}$ after hCG (A. B. Nascimento and M. C. Wiltbank, unpublished data). We speculated before this study that the large increase in $\mathrm{P} 4$ should produce a major benefit in the P4-deprived lactating cow; however, the low magnitude of the fertility of hCG-treated cows was disappointing, although consistent with the meta-analysis. It seems possible that the increase in P4 may be too late to benefit fertility in most cows. Based on a study comparing the relationship between the P4 concentration and early embryo survival on $\mathrm{d} 4$ to 8 , the authors found a linear and quadratic association between the probability of embryo survival and the P4 concentrations on d 4 to 6 after ovulation but did not find this association on $\mathrm{d} 7$ and 8 after ovulation (McNeill et al., 2006). Another report comparing the relationship between post-AI P4 and embryo survival, observed low P4 during d 5 to 7 associated with low fertility in dairy cows (Stronge et al., 2005). Delivery of exogenous $\mathrm{P} 4$ to increase circulating concentrations in the first few days after conception advances posthatching expansion and elongation of the conceptus (Garrett et al., 1988; Carter et al., 2008). In addition, size of the conceptus has a positive correlation with interferon tau secretion (Rizos et al., 2012) and is associated with earlier onset of interferon tau secretion (Mann et al., 2006). A recent paper also showed that hCG treatment of beef cows increased circulating P4 and embryo size on d 14 after estrus, although interferon activity by the embryos was not different (Rizos et al., 2012). An earlier P4 increase may be needed to optimally enhance embryo growth and fertility. From a practical standpoint, it seems possible that we could advance $\mathrm{hCG}$ treatment to $\mathrm{d} 4$, as most cows would have follicular deviation and ovulatory capacity by this time (Sartori et al., 2001). This could potentially produce an earlier increase in P4 due to hCG treatment, although a delay in the P4 increase of 3 to $5 \mathrm{~d}$ is likely due to the predictable delay in functional CL formation after hCG-induced ovulation. Earlier P4 supplementation strategies will likely require an exogenous source of $\mathrm{P} 4$, although the later P4 supplementation produced by the hCG-induced accessory CL has a modest positive effect on fertility. In agreement with several studies (Breuel et al., 1990; Fricke et al., 1993; Santos et al., 2001), treatment of cows with hCG on d 5 of the estrous cycle resulted in higher $\mathrm{P} 4$ concentrations during the mid-luteal phase than those in the controls. Substantial evidence exists that hCG binds to the LH receptor and is able to mimic the stimulatory effects of LH, such as ovulation of dominant follicles and increasing $\mathrm{P} 4$ production by 
small luteal cells (Niswender et al., 2000). Thus, the increase in $\mathrm{P} 4$ concentrations has been attributed to 2 potential effects of hCG. First, the clear effect of hCG on ovulation of a dominant follicle and production of an accessory CL that may increase total P4 production due to an increase in CL number. Second, several researchers indicate that treatment with hCG during the early estrous cycle enhances the subsequent size and luteal activity of the primary CL (Helmer and Britt, 1986; Stevenson et al., 2007; De Rensis et al., 2008; Rizos et al., 2012). However, our measurements in the present study did not observe an increase due to hCG in volume of the primary CL, although total CL volume was increased due to presence of the new accessory CL. These results are in agreement with Schmitt et al. (1996a), who did not find an effect of hCG on in vitro production of $\mathrm{P} 4$ by the primary CL removed on d 12 of the estrous cycle. Similarly, Santos et al. (2001) observed higher $\mathrm{P} 4$ concentrations after hCG treatment on $\mathrm{d} 5$ but no difference in the area or volume of the primary CL. Thus, our observations are consistent with some studies, but not other studies, that the increase in circulating $\mathrm{P} 4$ after $\mathrm{hCG}$ treatment is primarily due to an ovulation effect and increased number of CL and not due to a direct stimulatory effect of hCG on the primary CL.

Seasonal effects of hCG on fertility have been compared in 4 of the studies evaluated in the meta-analysis and in our field study. One study reported that hCG (d 4) reduced pregnancy loss between 27 and $39 \mathrm{~d}$ after AI during the summer months but not during other months, although no increase in absolute pregnancy rates on d 39 were observed in that study during any season of the year (Fischer-Tenhagen et al., 2010). In contrast, another study (Santos et al. (2001) found a tendency $(P=0.09)$ for an interaction between season and hCG treatment with increased fertility following hCG treatment of cows during the cool period (control $=34.2 \%$ vs. $\mathrm{hCG}=47.8 \%$ ), but not during the hot period (control $=44.1 \%$ vs. $\mathrm{hCG}=43.3 \%$ ). One elegant experiment utilized body temperature as the criteria for heat stress (rectal temperature $>39.7^{\circ} \mathrm{C}$ ). Treatment with hCG increased circulating $\mathrm{P} 4$ in cows that were heat-stressed and in cows that were not heatstressed. However, hCG enhanced fertility only in cows with lower rectal temperatures and not in cows exhibiting heat stress (Beltran and Vasconcelos, 2008). Logically, hCG treatment $5 \mathrm{~d}$ after AI would not enhance fertility in heat-stressed cows due to reduced fertilization (Sartori et al., 2002; Hackbart et al., 2010) and increased early embryonic death (Hansen and Arechiga, 1999) resulting in lack of a functional embryo at the time of hCG treatment. Nevertheless, our study and 2 other studies did not detect an effect of season on hCG treatment effects (Schmitt et al., 1996b; Vasconcelos et al., 2011). Heat stress (increased body temperature) might have been lessened in these studies due to lessdramatic increases in temperature-humidity conditions or to enhanced cooling systems.

Two major limitations of this research were noted and should be considered in designing future trials. First, no comparison of hCG dose was planned in the experiments and this may be a critical consideration in improving reproduction in lactating dairy cows with hCG treatment. Second, only the initial pregnancy diagnosis data were utilized in this research. The effects of hCG may be most apparent at later pregnancy diagnoses or even in evaluating percentage of cows that calve after a specific treatment. Future trials should be designed to overcome these important limitations.

\section{CONCLUSIONS}

Treatment with hCG at d 5 after AI seemed to have a small (3-3.5\% increase) but statistically significant effect on fertility in lactating Holstein cows. Similar results were observed in a meta-analysis of previously published studies and in a preplanned study of dairy cows that received hCG after synchronized ovulation and TAI. Unexpectedly, the fertility-enhancing effects of hCG in our field study were only observed in firstlactation cows, not in older cows.

\section{ACKNOWLEDGMENTS}

The authors thank the owners and employees at Larson Acres (Evansville, WI), Crave Brothers Dairy (Waterloo, WI), Wagner Dairy (Middleton, WI), Mystic View Dairy (Wilton, WI), Soaring Eagle Dairy (Newton, WI), and Sunburst Dairy (Belleville, WI) for their collaboration in this study. This research was supported by USDA-IFAFS grant 2001-52101-11252 and the Wisconsin State Experiment Station (Madison).

\section{REFERENCES}

Bamber, R. L., G. E. Shook, M. C. Wiltbank, J. E. Santos, and P. M. Fricke. 2009. Genetic parameters for anovulation and pregnancy loss in dairy cattle. J. Dairy Sci. 92:5739-5753.

Beltran, M. P., and J. L. M. Vasconcelos. 2008. Conception rate in Holstein cows treated with GnRH or hCG on the fifth day post artificial insemination during summer. Arq. Bras. Med. Vet. Zootec. $60: 580-586$.

Bisinotto, R. S., and J. E. P. Santos. 2011. The use of endocrine treatments to improve pregnancy rates in cattle. Reprod. Fertil. Dev. 24:258-266.

Breuel, K. F., J. C. Spitzer, C. E. Thompson, and J. F. Breuel. 1990. First-service pregnancy rate in beef heifers as influenced by human chorionic gonadotropin administration before and/or after breeding. Theriogenology 34:139-145.

Brusveen, D. J., A. P. Cunha, C. D. Silva, P. M. Cunha, R. A. Sterry, E. P. B. Silva, J. N. Guenther, and M. C. Wiltbank. 2008. Altering 
the time of the second gonadotropin-releasing hormone injection and artificial insemination (AI) during Ovsynch affects pregnancies per AI in lactating dairy cows. J. Dairy Sci. 91:1044-1052.

Caraviello, D. Z., K. A. Weigel, M. Craven, D. Gianola, N. B. Cook, K. V. Nordlund, P. M. Fricke, and M. C. Wiltbank. 2006. Analysis of reproductive performance of lactating cows on large dairy farms using machine learning algorithms. J. Dairy Sci. 89:4703-4722.

Carter, F., N. Forde, P. Duffy, M. Wade, T. Fair, M. A. Crowe, A. C. Evans, D. A. Kenny, J. F. Roche, and P. Lonergan. 2008. Effect of increasing progesterone concentration from Day 3 of pregnancy on subsequent embryo survival and development in beef heifers. Reprod. Fertil. Dev. 20:368-375.

De Rensis, F., E. Bottarelli, F. Battioni, T. Capelli, M. Techakumphu, I. Garcia-Ispierto, and F. Lopez-Gatius. 2008. Reproductive performance of dairy cows with ovarian cysts after synchronizing ovulation using $\mathrm{GnRH}$ or $\mathrm{hCG}$ during the warm or cool period of the year. Theriogenology 69:481-484.

De Rensis, F., F. Lopez-Gatius, I. Garcia-Ispierto, and M. Techakumpu. 2010. Clinical use of human chorionic gonadotropin in dairy cows: An update. Theriogenology 73:1001-1008.

Diskin, M. G., J. J. Murphy, and J. M. Sreenan. 2006. Embryo survival in dairy cows managed under pastoral conditions. Anim. Reprod. Sci. 96:297-311.

Dubuc, J., T. F. Duffield, K. E. Leslie, J. S. Walton, and S. J. Leblanc. 2012. Risk factors and effects of postpartum anovulation in dairy cows. J. Dairy Sci. 95:1845-1854.

Fischer-Tenhagen, C., G. Thiele, W. Heuwieser, and B. A. Tenhagen. 2010. Efficacy of a treatment with hCG 4 days after AI to reduce pregnancy losses in lactating dairy cows after synchronized ovulation. Reprod. Domest. Anim. 45:468-472.

Forde, N., M. E. Beltman, G. B. Duffy, J. P. Mehta, P. O'Gaora, J. F. Roche, P. Lonergan, and M. A. Crowe. 2011. Changes in the endometrial transcriptome during the bovine estrous cycle: Effect of low circulating progesterone and consequences for conceptus elongation. Biol. Reprod. 84:266-278.

Fricke, P. M., L. P. Reynolds, and D. A. Redmer. 1993. Effect of human chorionic gonadotropin administered early in the estrous cycle on ovulation and subsequent luteal function in cows. J. Anim. Sci. 71:1242-1246.

Gaja, A. O., K. Hamana, C. Kubota, and T. Kojima. 2008. Evaluation of the effect of a 3rd GnRH injection administered six days after the 2nd GnRH injection of Ovsynch on the reproductive performance of Japanese black cows. J. Vet. Sci. 9:273-279.

Garrett, J. E., R. D. Geisert, M. T. Zavy, and G. L. Morgan. 1988. Evidence for maternal regulation of early conceptus growth and development in beef cattle. J. Reprod. Fertil. 84:437-446.

Geisert, R. D., G. L. Morgan, E. C. Short Jr., and M. T. Zavy. 1992. Endocrine events associated with endometrial function and conceptus development in cattle. Reprod. Fertil. Dev. 4:301-305.

Giordano, J. O., M. C. Wiltbank, J. N. Guenther, R. Pawlisch, S. Bas, A. P. Cunha, and P. M. Fricke. 2012. Increased fertility in lactating dairy cows resynchronized with Double-Ovsynch compared with Ovsynch initiated $32 \mathrm{~d}$ after timed artificial insemination. J. Dairy Sci. 95:639-653.

Gümen, A., and M. C. Wiltbank. 2005. Length of progesterone exposure needed to resolve large follicle anovular condition in dairy cows. Theriogenology 63:202-218.

Hackbart, K. S., R. M. Ferreira, A. A. Dietsche, M. T. Socha, R. D. Shaver, M. C. Wiltbank, and P. M. Fricke. 2010. Effect of dietary organic zinc, manganese, copper, and cobalt supplementation on milk production, follicular growth, embryo quality, and tissue mineral concentrations in dairy cows. J. Anim. Sci. 88:3856-3870.

Hamza, T. H., H. C. van Houwelingen, and T. Stijnen. 2008. The binomial distribution of meta-analysis was preferred to model withinstudy variability. J. Clin. Epidemiol. 61:41-51.

Hanlon, D. W., G. M. Jarratt, P. J. Davidson, A. J. Millar, and V. L. Douglas. 2005. The effect of hCG administration five days after insemination on the first service conception rate of anestrous dairy cows. Theriogenology 63:1938-1945.
Hansen, P. J., and C. F. Arechiga. 1999. Strategies for managing reproduction in the heat-stressed dairy cow. J. Anim. Sci. 77(Suppl. 2):36-50.

Helmer, S. D., and J. H. Britt. 1986. Fertility of dairy cattle treated with human chorionic gonadotropin (hCG) to stimulate progesterone secretion. Theriogenology 26:683-695.

Hugentobler, S. A., J. M. Sreenan, P. G. Humpherson, H. J. Leese, M. G. Diskin, and D. G. Morris. 2010. Effects of changes in the concentration of systemic progesterone on ions, amino acids and energy substrates in cattle oviduct and uterine fluid and blood. Reprod. Fertil. Dev. 22:684-694.

Kendall, N. R., A. P. Flint, and G. E. Mann. 2009. Incidence and treatment of inadequate postovulatory progesterone concentrations in repeat breeder cows. Vet. J. 181:158-162.

Lonergan, P. 2011. Influence of progesterone on oocyte quality and embryo development in cows. Theriogenology 76:1594-1601.

Lopez, H., L. D. Satter, and M. C. Wiltbank. 2004. Relationship between level of milk production and estrous behavior of lactating dairy cows. Anim. Reprod. Sci. 81:209-223.

Lucy, M. C. 2001. Reproductive loss in high-producing dairy cattle: Where will it end? J. Dairy Sci. 84:1277-1293.

Mann, G. E., M. D. Fray, and G. E. Lamming. 2006. Effects of time of progesterone supplementation on embryo development and interferon-tau production in the cow. Vet. J. 171:500-503.

McNeill, R. E., M. G. Diskin, J. M. Sreenan, and D. G. Morris. 2006. Associations between milk progesterone concentration on different days and with embryo survival during the early luteal phase in dairy cows. Theriogenology 65:1435-1441.

Moreira, F., C. Orlandi, C. A. Risco, R. Mattos, F. Lopes, and W. W. Thatcher. 2001. Effects of presynchronization and bovine somatotropin on pregnancy rates to a timed artificial insemination protocol in lactating dairy cows. J. Dairy Sci. 84:1646-1659.

Nascimento, A. B., A. H. Souza, J. N. Guenther, F. P. Costa, R. Sartori, and M. C. Wiltbank. 2012. Effects of treatment with human chorionic gonadotrophin or intravaginal progesterone-releasing device after $\mathrm{AI}$ on circulating progesterone concentrations in lactating dairy cows. Reprod. Fertil. Dev. http://dx.doi.org/10.1071/ RD12104. [Epub ahead of print].

Niswender, G. D., J. L. Juengel, P. J. Silva, M. K. Rollyson, and E. W. McIntush. 2000. Mechanisms controlling the function and life span of the corpus luteum. Physiol. Rev. 80:1-29.

Perry, G. A., M. F. Smith, M. C. Lucy, J. A. Green, T. E. Parks, M. D. MacNeil, A. J. Roberts, and T. W. Geary. 2005. Relationship between follicle size at insemination and pregnancy success. Proc. Natl. Acad. Sci. USA 102:5268-5273.

Pursley, J. R., and J. P. N. Martins. 2011. Impact of circulating concentrations of progesterone and antral age of the ovulatory follicle on fertility of high-producing lactating dairy cows. Reprod. Fertil. Dev. 24:267-271.

Pursley, J. R., M. O. Mee, and M. C. Wiltbank. 1995. Synchronization of ovulation in dairy cows using PGF2alpha and GnRH. Theriogenology 44:915-923.

Rizos, D., S. Scully, A. K. Kelly, A. D. Ealy, R. Moros, P. Duffy, A. Al Naib, N. Forde, and P. Lonergan. 2012. Effects of human chorionic gonadotropin administration on day 5 after oestrus on corpus luteum characteristics, circulating progesterone and conceptus elongation in cattle. Reprod. Fertil. Dev. 24:472-481.

Sangsritavong, S., D. K. Combs, R. Sartori, L. E. Armentano, and M. C. Wiltbank. 2002. High feed intake increases liver blood flow and metabolism of progesterone and estradiol-17beta in dairy cattle. J. Dairy Sci. 85:2831-2842.

Santos, J. E., W. W. Thatcher, L. Pool, and M. W. Overton. 2001. Effect of human chorionic gonadotropin on luteal function and reproductive performance of high-producing lactating Holstein dairy cows. J. Anim. Sci. 79:2881-2894.

Sartori, R., P. M. Fricke, J. C. Ferreira, O. J. Ginther, and M. C Wiltbank. 2001. Follicular deviation and acquisition of ovulatory capacity in bovine follicles. Biol. Reprod. 65:1403-1409.

Sartori, R., R. Sartor-Bergfelt, S. A. Mertens, J. N. Guenther, J. J. Parrish, and M. C. Wiltbank. 2002. Fertilization and early em- 
bryonic development in heifers and lactating cows in summer and lactating and dry cows in winter. J. Dairy Sci. 85:2803-2812.

Schmitt, E. J., C. M. Barros, P. A. Fields, M. J. Fields, T. Diaz, J. M. Kluge, and W. W. Thatcher. 1996a. A cellular and endocrine characterization of the original and induced corpus luteum after administration of a gonadotropin-releasing hormone agonist or human chorionic gonadotropin on day five of the estrous cycle. J. Anim. Sci. 74:1915-1929.

Schmitt, E. J., T. Diaz, C. M. Barros, R. L. de la Sota, M. Drost, E. W. Fredriksson, C. R. Staples, R. Thorner, and W. W. Thatcher. 1996b. Differential response of the luteal phase and fertility in cattle following ovulation of the first-wave follicle with human chorionic gonadotropin or an agonist of gonadotropin-releasing hormone. J. Anim. Sci. 74:1074-1083.

Shams-Esfandabadi, N., A. Shirazi, P. Mirshokrai, and M. Bonyadian. 2007. Influence of hCG administration after AI on conception rates and serum progesterone concentration in cattle. Pak. J. Biol. Sci. 10:2709-2713.

Souza, A. H., H. Ayres, R. M. Ferreira, and M. C. Wiltbank. 2008. A new presynchronization system (Double-Ovsynch) increases fertility at first postpartum timed AI in lactating dairy cows. Theriogenology 70:208-215.

Stevenson, J. S., A. P. Phatak, I. Rettmer, and R. E. Stewart. 1993. Postinsemination administration of receptal: Follicular dynamics, duration of cycle, hormonal responses, and pregnancy rates. J. Dairy Sci. 76:2536-2547.

Stevenson, J. S., M. A. Portaluppi, D. E. Tenhouse, A. Lloyd, D. R. Eborn, S. Kacuba, and J. M. DeJarnette. 2007. Interventions after artificial insemination: Conception rates, pregnancy survival, and ovarian responses to gonadotropin-releasing hormone, human chorionic gonadotropin, and progesterone. J. Dairy Sci. 90:331-340.

Stronge, A. J., J. M. Sreenan, M. G. Diskin, J. F. Mee, D. A. Kenny, and D. G. Morris. 2005. Post-insemination milk progesterone concentration and embryo survival in dairy cows. Theriogenology 64:1212-1224.

Vasconcelos, J. L., O. G. Sa Filho, P. L. Justolin, P. Morelli, F. L. Aragon, M. B. Veras, and S. Soriano. 2011. Effects of postbreeding gonadotropin treatments on conception rates of lactating dairy cows subjected to timed artificial insemination or embryo transfer in a tropical environment. J. Dairy Sci. 94:223-234.

Vasconcelos, J. L., R. Sartori, H. N. Oliveira, J. G. Guenther, and M. C. Wiltbank. 2001. Reduction in size of the ovulatory follicle reduces subsequent luteal size and pregnancy rate. Theriogenology 56:307-314.

Walton, J. S., G. W. Halbert, N. A. Robinson, and K. E. Leslie. 1990. Effects of progesterone and human chorionic gonadotrophin administration five days postinsemination on plasma and milk concentrations of progesterone and pregnancy rates of normal and repeat breeder dairy cows. Can. J. Vet. Res. 54:305-308.

Wiltbank, M., H. Lopez, R. Sartori, S. Sangsritavong, and A. Gumen. 2006. Changes in reproductive physiology of lactating dairy cows due to elevated steroid metabolism. Theriogenology 65:17-29.

Wiltbank, M. C., A. H. Souza, P. D. Carvalho, R. W. Bender, and A. B. Nascimento. 2011. Improving fertility to timed artificial insemination by manipulation of circulating progesterone concentrations in lactating dairy cattle. Reprod. Fertil. Dev. 24:238-243. 